\title{
Manometric investigation of anorectal function in early and late stage Parkinson's disease
} Gabrio Bassotti, Dario Maggio, Edda Battaglia, Ornella Giulietti, Fabrizio Spinozzi,
Gianpaolo Reboldi, Anna Maria Serra, Giorgio Emanuelli, Giuseppe Chiarioni
Laboratorio di Motilità Intestinale, Sezione di Gastroenterologia ed Epatologia, Via Enrico Dal Pozzo, 06100

Perugia, Italy

G Bassotti

F Spinozzi

Gerontology and Geriatrics Section

D Maggio

Internal Medicine, Angiology and Atherosclerosis

Diseases Section, Department of Clinical and Experimental

Medicine

O Giulietti

Department of Internal Medicine, Endocrine and

Metabolic Sciences, University of Perugia Medical School, Italy

G Reboldi

Department of Clinical Pathophysiology, University of Torino Medical School, Italy

E Battaglia

A M Serra

G Emanuelli

Division of Gastroenterological Rehabilitation, Valeggio sul Mincio Hospital, University of Verona Medical School, Italy

G Chiarioni

Correspondence to: Dr Gabrio Bassotti gabassot@tin.it

Received 12 October 1999 and in revised form

31 January 2000

Accepted 9 February 2000

\begin{abstract}
Abnormal gastrointestinal function is relatively frequent in Parkinson's disease, and constipation is a disturbing symptom in many patients. However, it remains to be established whether anorectal abnormalities are characteristic of the late stages of the disease. Clinical and anorectal manometric function were investigated in groups of early and late stage parkinsonian patients. Thirty one patients (19 men, 12 women, age range 22 to 89 years) entered the study. The disease severity was assessed by Hoehn and Yahr staging: there were four $(12.9 \%)$ stage $I$, seven $(22.6 \%)$ stage II, $10(32.2 \%)$ stage III, and $10(32.2 \%)$ stage IV patients. Anorectal variables were measured by standard manometric equipment and techniques. Values obtained in early stage patients (Hoehn and Yahr stage I and II) were compared with those obtained in late stage patients (Hoehn and Yahr stage III and IV). Overall, more than $70 \%$ of patients complained of chronic constipation, with chronic laxative use reported in more than $30 \%$. Late stage patients were slightly older than their early stage counterparts. Pelvic floor dyssynergia was documented in more than $60 \%$ of patients. Manometric variables were not different in the two groups. In conclusion, defecatory dysfunction is frequent in Parkinson's disease, it is not confined to late stage patients, and it is found early in the course of the disease. This has potential implications for a targeted therapeutic approach.
\end{abstract}

(F Neurol Neurosurg Psychiatry 2000;68:768-770)

Keywords: anorectal; constipation; manometry; Parkinson's disease

Abnormal gastrointestinal function is a well established feature of Parkinson's disease. ${ }^{1}$ Among gastrointestinal symptoms, constipation is one of the most common, and it is complained of by $30 \%$ to $50 \%$ of patients with Parkinson's disease. ${ }^{2}$ It is worth noting that the characteristics of constipation and defecatory difficulties were described by James Parkinson in his original monograph on the disease. ${ }^{3}$ In advanced cases, colonic motor abnormalities may progress up to a megacolon, that may result in fatal perforation or pseudoobstruction. ${ }^{4}$

A few studies show that in patients with Parkinson's disease both an impaired large bowel transit and abnormal distal defecatory mechanisms may be present..$^{5-7}$ The presence of Lewy bodies and a defect of dopaminergic neurons in the enteric nervous system of these patients has been recently demonstrated. ${ }^{8}{ }^{9}$ However, previously published series included patients with relatively good functional capacity, and it is therefore unknown whether patients with more advanced disease may have different anorectal abnormalities.

Purposes of the present study were (1) to investigate anorectal function in a group of patients with Parkinson's disease with mild to advanced stage of the disease, and (2) to compare early and late stage Parkinson's disease groups for anorectal function.

\section{Patients and methods}

PATIENTS

Thirty one patients with Parkinson's disease ( 19 men, 12 women, age range 22 to 89 years) were recruited for the study. The severity of the disease was determined by the Hoehn and Yahr stage, an objective rating based on the presence of tremor, rigidity, bradykinesia, and postural instability. ${ }^{10}$ There were four $(12.9 \%)$ stage I, seven $(22.6 \%)$ stage II, 10 (32.2\%) stage III, and $10(32.2 \%)$ stage IV patients. All patients were given a standard questionnaire to assess the presence of chronic constipation, defecatory dysfunction, and laxative use. Chronic constipation was defined as one or fewer evacuations a week. ${ }^{11}$ Defecatory dysfunction was assessed on the basis of straining at stools, and the presence of straining at least once a week was considered abnormal. ${ }^{7}$ Patients taking antiparkinsonian medications withheld them on the day of manometric testing. To exclude mechanical causes of constipation, as well as megarectum or megacolon, each patient underwent double contrast barium enema.

\section{METHODS}

Anorectal manometry was carried out according to a previously described standard technique and instrumentation. ${ }^{12} \mathrm{~A}$ nine lumen 
commercially available PVC anorectal catheter with terminal rubber balloon (Arndorfer Medical Specialties, type ARM-3), connected via physiological pressure transducers (Bell and Howell, type 4-327-I) to a low compliance infusion pump (Arndorfer Medical Specialties, perfusion rate $0.5 \mathrm{ml} / \mathrm{min}$ ) and to a Beckman R-611 Dynograph Recorder (paper speed: 1 $\mathrm{mm} / \mathrm{s}$ ), was used. Four $1 \mathrm{~cm}$ spaced recording points were selected for recording anorectal pressures. After recording the rectoanal pressure profile with stepwise withdrawal $(1 \mathrm{~cm} / 30$ s), the anal resting tone was recorded for 5 minutes with the catheter fixed at the highest pressure point obtained during two pull throughs. Then the rectosphincteric inhibitory reflex was evaluated by inflating and rapidly deflating the catheter balloon with 10, 20, 30, 50,70 , or $100 \mathrm{ml}$ air. If the patients did not report any defecatory sensation threshold (see below for definition) during this part of the procedure, the catheter balloon was progressively inflated $(50 \mathrm{ml} / \mathrm{min})$ up to a maximum of $600 \mathrm{ml}$ to test this sensation.

Finally, the sphincteric response to straining was assessed by asking the subjects to strain as if to defecate three times at 1 minute intervals.

\section{ETHICAL CONSIDERATIONS}

After detailed explanations about the aims of the investigation and about the tests to be carried out, each patient gave informed consent, and the procedures were performed in accordance with the local ethical guidelines following the recommendations of the Declaration of Helsinki.

\section{DATA ANALYSIS}

All tracings were analysed blindly by one of us. The following variables of anorectal manometry were taken into account: (1) maximum basal pressure of the internal anal sphincter, defined as the mean of the highest resting pressures recorded from each of the four ports during the two pull throughs ${ }^{13}$; (2) minimum relaxation volume, defined as the lower quantity of air inflated in the rectal balloon necessary to elicit the rectoanal inhibitory reflex, a drop in pressure $>5 \mathrm{~mm} \mathrm{Hg}$, which represents relaxation of the internal sphincter ${ }^{14}$; (3) defecatory sensation threshold, defined as the smallest volume at which the first desire to defecate was reported by the patient ${ }^{15}$; (4) response to straining, evaluated by noting whether straining to defecate caused a decrease in intra-anal pressure (normal response) or a paradoxical increase in intra-anal pressure. ${ }^{16}$

\section{STATISTICAL ANALYSIS}

The above variables were calculated for the entire Parkinson's disease group and for subsets of patients. In particular, two groups were compared, which included the early (patients with I and II stage) and late (patients with III and IV stage) stage of the disease. Differences between groups were assessed by nonparametric tests, by employing the MannWhitney $U$ test for unpaired data and the test for differences between proportions, where appropriate. Values of $p<0.05$ were chosen for
Table 1 Demographic, clinical, and manometric variables in 31 patients with Parkinson's disease

\begin{tabular}{ll}
\hline Sex $(\mathrm{M} / \mathrm{F})$ & $19 / 12$ \\
Age $(\mathrm{y})$ & $73(22-89)$ \\
Constipation & $22 / 31(71 \%)$ \\
Straining & $14 / 31(45 \%)$ \\
Chronic laxative use & $10 / 31(32.2 \%)$ \\
IAS pressure (mm Hg) & $50.5(10-91)$ \\
MRV (ml) & $20(0-40)$ \\
DST (m) & $90(10-600)$ \\
dyssynergia & $19 / 31(61.3 \%)$ \\
\hline
\end{tabular}

IAS=internal anal sphincter; $M R V=$ minimum relaxation volume; DST=defecatory sensation threshold.

Table 2 Demographic, clinical, and manometric variables in early and late stages of Parkinson's disease (PD)

\begin{tabular}{llll}
\hline & Early PD & Late PD & $p$ Value \\
\hline Sex $(\mathrm{M} / \mathrm{F})$ & $7 / 4$ & $12 / 8$ & - \\
Age $(\mathrm{y})$ & $65(22-89)$ & $76.5(60-88)$ & 0.052 \\
Constipation & $6 / 11(54.5 \%)$ & $16 / 20(80 \%)$ & NS \\
$\quad$ Straining & $3 / 11(27.3 \%)$ & $11 / 20(55 \%)$ & NS \\
IAS pressure & & & \\
$\quad(\mathrm{mm} \mathrm{Hg})$ & $62(15.5-91)$ & $49.7(10-88)$ & $\mathrm{NS}$ \\
$\mathrm{MRV}(\mathrm{ml})$ & $30(10-30)$ & $20(0-40)$ & NS \\
$\begin{array}{l}\text { DST }(\mathrm{ml}) \\
\text { dyssynergia }\end{array}$ & $100(40-170)$ & $70(10-600)$ & NS \\
\hline
\end{tabular}

Abbreviations as in table 1.

rejection of the null hypothesis. Data are expressed as median (range).

\section{Results}

Table 1 shows the demographic, clinical, and manometric variables of the patients studied. Overall, more than $70 \%$ of patients complained of chronic constipation, with defecatory dysfunction reported in $45 \%$ and chronic laxative use in more than $30 \%$. Manometric variables were similar to those previously reported for chronically constipated patients in our laboratory. ${ }^{12}$ Pelvic floor dyssynergia was a frequent abnormality in patients with Parkinson's disease, being described in more than $60 \%$ of our cases. One stage III patient exhibited a hypercontractile response (prominent and prolonged contraction without any evidence of relaxation) of the internal anal sphincter. ${ }^{7}$ One stage I female patient, 22 years old and without previous anal surgery, complained of faecal incontinence: her average anal sphincter pressure was less than $20 \mathrm{~mm} \mathrm{Hg}$.

Table 2 shows the demographic, clinical, and manometric variables of early (stages I and II) and late (stages III and IV) stages of the disease. Manometric variables were not different in the two groups. Patients with late stage Parkinson's disease were slightly older than early stage patients.

\section{Discussion}

Gastrointestinal motility disorders are frequent in patients with Parkinson's disease, manifesting mainly as dysphagia, gastric emptying abnormalities, and constipation. ${ }^{17}$ The number of patients investigated up to the present in single studies are, however, scarce, and usually irrespective of the various stages of the disease. The present study, carried out in a fairly large group of patients with Parkinson's disease, confirms previous findings that a high percentage of these patients complain of constipation. ${ }^{18}$ However, to the best of our knowledge no study has compared anorectal variables in 
early and late stage patients. Although we hypothesised that patients with late stage Parkinson's disease would have a greater impairment in these variables, it turned out that this was not the case. Indeed, for manometric variables no significant differences were found between patients with early and late stages of the disease.

On the basis of these results, we hypothesise that anorectal involvement in Parkinson's disease starts early in the course of the disease in a high proportion of patients. This is also supported by the recent description of electromyographic sphincteric abnormalities in patients with newly diagnosed Parkinson's disease. $^{19}$

The manometric variables we analysed were similar to those we found in patients complaining of chronic idiopathic constipation. ${ }^{12}$ Such similarities have also been recently reported by Ashraf et $a l,{ }^{20}$ who, however, noted a significant difference only in the squeeze response. Although we have not included this test in the study procedures, such a response was tested in seven patients with late stage disease and was abnormal (data not shown). Therefore, we agree with Ashraf et al that many of these patients may have direct involvement of the pelvic floor musculature.

The fact that these abnormalities apparently have an early onset in Parkinson's disease may have therapeutic implications. For instance, the benefit of cisapride in such patients tends to fade in the long run, ${ }^{21}$ and fibre supplementation does not modify colonic transit and anorectal function, ${ }^{22}$ although it improves the delivery of dopaminergic agents and promotes more predictable symptom control. ${ }^{23}$ Therefore, a more tailored and pathophysiologically oriented therapeutic approach is advisable. Interestingly, there is evidence that visceral symptoms in Parkinson's disease may respond acutely to the parenteral administration of the dopaminergic agent apomorphine, ${ }^{24}$ and this drug has actually been employed on an as needed basis to improve micturition and defecation in these patients. ${ }^{25}$ More recently, the use of botulinum toxin injection has been proposed to treat outlet type constipation in Parkinson's disease. ${ }^{26}$ This seems to be a frequent pathophysiological mechanism of constipation in such patients, and in our series was documented in more than $60 \%$ of cases. Although this approach needs validation in larger groups and its efficacy in the disease course remains to be established, it might represent a rationale attempt towards a more disease targeted approach.

Indeed, a timely therapeutic intervention on constipation (due to the appearance of anorectal abnormalities in early stages of Parkinson's disease) might lead to a better quality of life and to fewer complications (for example, faecal impaction, fissures) in these patients.

1 Edwards LL, Quigley EMM, Pfeiffer RF. Gastrointestinal dysfunction in Parkinson's disease: frequency and pathophysiology. Neurology 1992;42:726-32.

2 Bassotti G, De Giorgio R, Stanghellini V, et al. Constipation: a common problem in patients with neurological abnormalities. Italian fournal of Gastroenterology and Hepatology 1998;30:542-8.

3 Parkinson J. An essay on the shaking palsey. London: Whittingham and Rowland, 1817

4 Bassotti G, Gaburri M, Pelli MA, et al. La sindrome da pseudoostruzione isolata del colon. Medicina (Rivista EMI) 1986;6:347-50

5 Mathers SE, Kempster PA, Swash M, et al. Constipation and paradoxical puborectalis contraction in anismus and
Parkinson's disease: a dystonic phenomenon? $f$ Neurol Parkinson's disease: a dystonic phen
Neurosurg Psychiatry 1988;51:1503-7.

6 Jost WH, Schimrigk K. Constipation in Parkinson's disease. Klin Wochenschr 1991;69:906-9.

7 Edwards LL, Quigley EMM, Harned RK, et al. Characterization of swallowing and defecation in Parkinson's disease. Am $\mathcal{F}$ Gastroenterol 1994;89:15-25.

8 Wakabayashi K, Takahashi H, Ohama E, et al. Parkinson's disease: an immunoistochemical study of Lewy body containing neurons in the enteric nervous system. Acta Neuropathol 1990;79:581-3.

9 Singaram C, Ashraf W, Gaumnitz EA, et al. Dopaminergic defect of enteric nervous system in Parkinson's disease defect of enteric nervous system in Parkinson's disease
patients with chronic constipation. Lancet 1995;346:861-4.

10 Hoehn MM, Yahr MD. Parkinsonism: onset, progression and mortality. Neurology 1967;17:427-42.

11 Bassotti G, Germani U, Fiorella S, et al. Intact colonic motor response to sudden awakening from sleep in patients with chronic idiopathic (slow-transit) constipation. Dis Colon Rectum 1998;41:1550-6.

12 Bassotti G, Chiarioni G, Vantini I, et al. Anorectal manometric abnormalities and colonic propulsive impairment in patients with severe chronic idiopathic constipation. Dig Dis Sci 1994;39:1558-64.

13 Chiarioni G, Bassotti G, Germani U, et al. Idiopathic megarectum in adults. An assessment of manometric and radiologic variables. Dig Dis Sci 1995;40:2286-92.

14 Dickinson VA. Maintenance of anal continence. A review of pelvic floor physiology. Gut 1978;19:1163-74.

15 Pescatori M, Parks AG. The sphincteric and sensory components of preserved continence after ileoanal reservoir. Surg Gynecol Obstet 1984;158:517-21.

16 Whitehead WE, Chaussade S, Corazziari E, et al. Report of an international workshop on management of constipation. Gastroenterology International 1991;4:99-113.

17 Jost WH. Gastrointestinal motility problems in patients with Parkinson's disease. Effects of antiparkinsonian treatment and guidelines for management. Drugs Aging 1997;10:24958.

18 Edwards LL, Pfeiffer RF, Quigley EMM, et al. Gastrointestinal symptoms in Parkinson's disease. Mov Disord 1991;6:151-6.

19 Jost WH, Schrank B. Defecatory disorders in de novo Parkinsonians. Colonic transit and electromyogram of the external anal sphincter. Wien Klin Wochenschr 1998;21: 535-7.

20 Ashraf W, Pfeiffer RF, Quigley EM. Anorectal manometry in the assessment of anorectal function in Parkinson's disease: a comparison with chronic idiopathic constipation. Mov Disord 1994;9:655-63.

21 Jost WH, Schimrigh K. Long-term results with cisapride in Parkinson's disease. Mov Disord 1997;12:423-5.

22 Ashraf W, Pfeiffer RF, Park F, et al. Constipation in Parkinson's disease: objective assessment and response to psyllium. Mov Disord 1997;12:946-51.

23 Astarloa R, Mena MA, Sanchez V, et al. Clinical and pharmacokinetic effects of a diet rich in insoluble fiber on pharmacokinetic effects of a diet rich in insoluble fiber on

24 Edwards LL, Quigley EM, Harned RK, et al. Defecatory function in Parkinson's disease: response to apomorphine. Ann Neurol 1993;33:490-3.

25 Christmas TJ, Kempster PA, Chapple CR, et al. Role of subcutaneous apomorphine in parkinsonian voiding dysfunction. Lancet 1988;ii:1451-3.

26 Albanese A, Maria G, Bentivoglio AR, et al. Severe constipation in Parkinson's disease relieved by botulinum toxin. Mov Disord 1997;12:764-6. 